\title{
Effect of Die Design Parameters on Thinning of Sheet Metal in the Deep Drawing Process
}

\author{
H. Zein, M. El-Sherbiny", M. Abd-Rabou, M. El Shazly \\ Mechanical Design and Production Department, Faculty of Engineering, Cairo University, Giza, Egypt \\ *Corresponding author: mgsherbiny@yahoo.com
}

Received December 30, 2012; Revised April 14, 2013; Accepted April 15, 2013

\begin{abstract}
Prediction of the forming results, determination of the thickness distribution and the thinning of the sheet metal blank will decrease the production cost through saving material and production time. In this paper, A Finite Element (FE) model is developed for the 3-D numerical simulation of deep drawing process (Parametric Analysis) by using ABAQUS/EXPLICIT FEA program with the proper material properties (anisotropic material) and simplified boundary conditions. The FE results are compared with experimental results for validation. The developed model can predict the thickness distribution and thinning of the blank with the die design parameters (geometrical and physical parameters). Furthermore, with numerical simulation, working parameters can be optimized without expensive shop trials.
\end{abstract}

Keywords: finite element, parametric analysis, geometrical parameters, thickness distribution, thinning

\section{Introduction}

Currently, the demand for metal containers in the world is in the order of 410 billion units per annum. Out of this, drink cans account for 320 billion and processed food cans account for 75 billion. It is also known, that for the majority of food and drink containers, the cost of the processed metal accounts for $50-70 \%$ of the total cost [1]. From the manufacturer's point of view, a reduction in material usage is of massive importance to cost reductions.

Reduction of material can be done by decreasing the wall thickness of the containers, whilst also retaining adequate strength to allow the container to serve its purpose, without fear of failure. The designer must meet these expectations, but also, must determine the material requirements and properties which are suitable for the food or drink being packaged. Traditionally, this process, as well as most metal forming techniques have been tested experimentally using trial-and-error or empirical methods, which are expensive and time consuming approaches, as dies, blank holders and punches need to be manufactured.

The objective of the work is to successfully simulate the deep drawing process and validate the results, by making a comparison with previously published literature. The literature contains both experimental and numerical results which are in agreement with each other and therefore is being set as the benchmark to for comparison purposes.

The incentive for doing this research is that deep drawing has come to a stage in the current industrialized world that requires the most efficient, low-cost, manufacturing route to be taken at all times.
The successful simulation of the deep drawing process is very much dependent on successful modeling of the deep drawing process for numerical analysis.

By making use of finite element analysis and statistical methods, the prediction of results such as the punch force, the blank holder force, the thickness distribution through sections of the metal and the lubrication requirements can be determined. This can significantly reduce the production costs, for higher quality containers by reducing the lead time to production and provides engineers the ability to promptly respond to market changes. In doing this, the level of knowledge in how various materials interact at the contact surfaces are enhanced, and the data for dealing with specific materials are also increased, which is another positive outcome.

The first of these works is published by Colgan and Monaghan [2] which has taken a statistical approach, based on experimental design using orthogonal arrays to ascertain which factors most influence the deep drawing process. The geometries for the deep drawing process have been reproduced, and a critical comparison was made for the products. 400 tests were carried out on blanks cut from drawing quality mild steel EN10130 FeP01 of 1mm thickness. The authors explain that for the experimental component of the research, hydraulic cylinders were used to deliver the blank holder force. They also reported that a pressure gauge was used to measure the pressure in the cylinders in conjunction with a needle valve. Although providing adequate results, they suggested, it would be desirable to employ the use of strain gauges in this instance, so as to gain a higher level of accuracy and confidence in the values obtained.

This work established that the punch/die radii have the greatest effect on the thickness of the formed mild steel 
cups. It was made apparent that the smaller the die radii, the greater the force on the blank, resulting in thinner wall thicknesses. It was also shown that the type of lubrication is very much affecting the force on the punch. Although Colgan and Monahan's work [2], concluded that the die radii were noted as a prominent factor, they did not provide enough substance to account for other factors affecting the deep drawing process.

The problem is also addressed, in another approach, by Demirci et al, [3] for the deep drawing process of AL1050 by performing experiments and finite element analysis using ANSYS/LS-DYNA, investigating the effects of the blank holder forces on differences in the cup wall thickness. The paper shows that under constant pressure the base of drawn cups remains at a constant value until thickness drops dramatically near the cup corners and follows exponential variation towards the outer edge on the cup flange. Taking into account the anisotropic properties of the material they concluded that forces exceeding 10MPa may result in tearing in the cup walls.

A paper published by Waleed Khalid Jawad [4] confirms the previously stated point that increasing the punch radii can slightly decrease the punch load and vice versa. He investigated the effects of punch radii on maintaining the interfacial contact between the punch and the blank, and punch load on thickness through a section of the drawn cup, and finally predicted the resulting localized strain and stress distribution. He concluded that frictional forces act mainly through the edge of the punch in a shearing manner, with little effect on the flat section.

Vladimirov et al [5] presented the derivation of a finite strain material model for plastic anisotropy and nonlinear kinematic and isotropic hardening. The work is applied numerically to the drawing of cylindrical and square shaped cups. They show that the numerical simulations, can be suitably extracted from the complex mathematical material models and that the phenomena of anisotropic properties can still be accounted for even with large deformations. They further go on to show the applicability of the mathematical work to account for the occurrence of earring during the drawing process.

Fereshteh-Saniee and Montazeran [6] predicted forming load, by using various finite element types, and the strain thickness distributions are produced, as reported in [4]. The authors also show that the use of shell 51 elements of the finite element package give a much higher agreement with the experimental results, as compared with the results using visco solid 106 elements. In making these comparisons, Fereshteh-Saniee and Montazeran use a formula derived by Siebel in [7] to produce an analytical solution to which the level of agreement between the various methods can generally be accepted.

Meguid and Refaat [8] used a method of variation inequalities to develop an analytical method to model the frictional contact in elastoplastic models which undergo large deformations. The effect of nonlinearities arising due to either the geometry or the materials used in the model is handled by using the updated Lagrange formulation.

Having arrived at a point where the material can be modeled to a very high degree of accuracy and the forming loads can be predicted to complete the drawing process, one may consider various frictional combinations at the contacting surfaces aiming at minimizing such forming loads, and hence cost analysis can be carried out for the manufacturing process of the container.

This paper intends to approach the deep drawing process of thin walled, mild steel, cylindrical containers, by means of a finite element analysis.

\section{Simulation of Deep Drawing Process}

\subsection{Finite Element Model}

Figure 1 shows a sketch for drawing a circular cup. The process is described in the following steps: The circular blank is inserted between die and blank holder; the punch move downwards; the diameter of the blank decreases with the blank being drawn into the die cavity; the flange of the blank form the perpendicular wall of the cup and the center part of the blank form the bottom of the cup. The important dimensions, Figure 2, of the blank, die, punch, and blank holder are shown in Table 1.

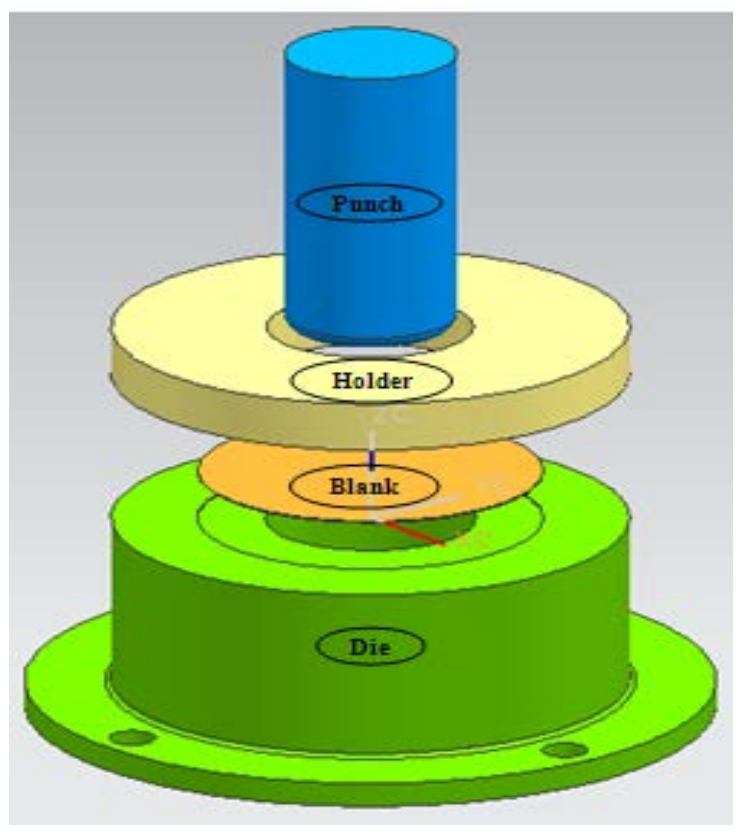

Figure 1. Sketch of the drawing die assembly 


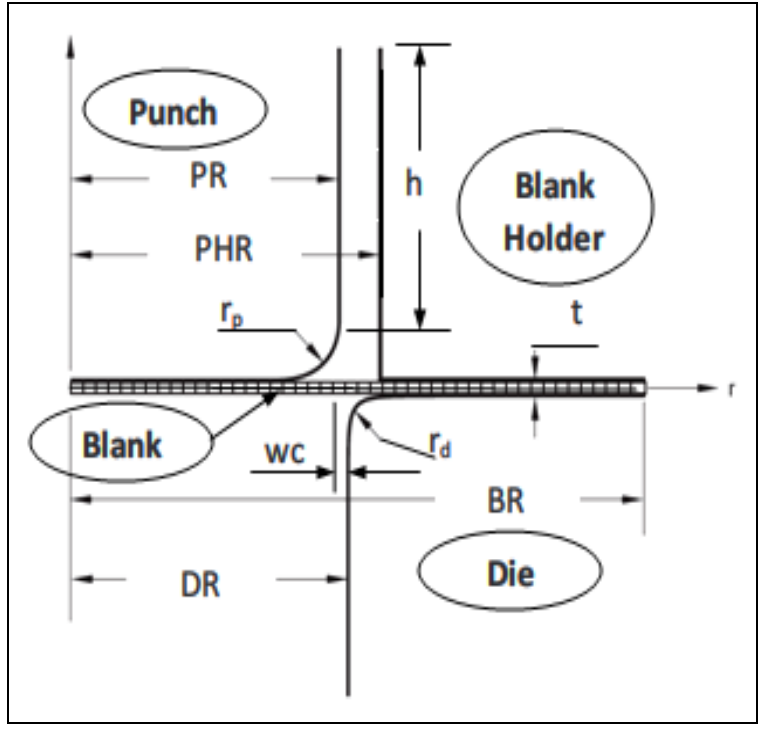

Figure 2. Geometry of drawing die assembly

Due to the symmetry, the numerical analysis of the deep-drawing process was performed by using only one quarter of 3D numerical model to reduce the computational time. The model is shown in Figure 3. Discrete rigid form was used to model the punch, die and holder, whose motion was governed by the motion of a single node, known as the rigid body reference node. Die, punch, and holder were meshed with R3D4 elements. Therefore, only the blank sheet metal (224mm diameter $\mathrm{x}$ $1 \mathrm{~mm}$ thickness) was considered deformable with a planar shell base and meshed with reduced integration S4R shell type element [9].

Table 1. Basic Geometrical Parameters

\begin{tabular}{|c|c|}
\hline Table 1. Basic Geometrical Parameters \\
\begin{tabular}{|c|c|}
\hline Parameter & $\begin{array}{c}\text { Dimension } \\
\text { in mm }\end{array}$ \\
\hline Blank size radius (BR) & 112 \\
\hline Blank thickness (t) & 1 \\
\hline Punch radius (PR) & 56 \\
\hline Punch nose radius ( $\mathrm{r}_{\mathrm{p}}$ ) & 4 \\
\hline Die radius (DR) & 57.67 \\
\hline Die shoulder radius ( $\mathrm{r}_{\mathrm{d}}$ ) & 6 \\
\hline Radial clearance between punch radius and die \\
radius (wc)
\end{tabular} & 1.67 \\
\hline Cup height of the first draw (h) & 63.69 \\
\hline
\end{tabular}

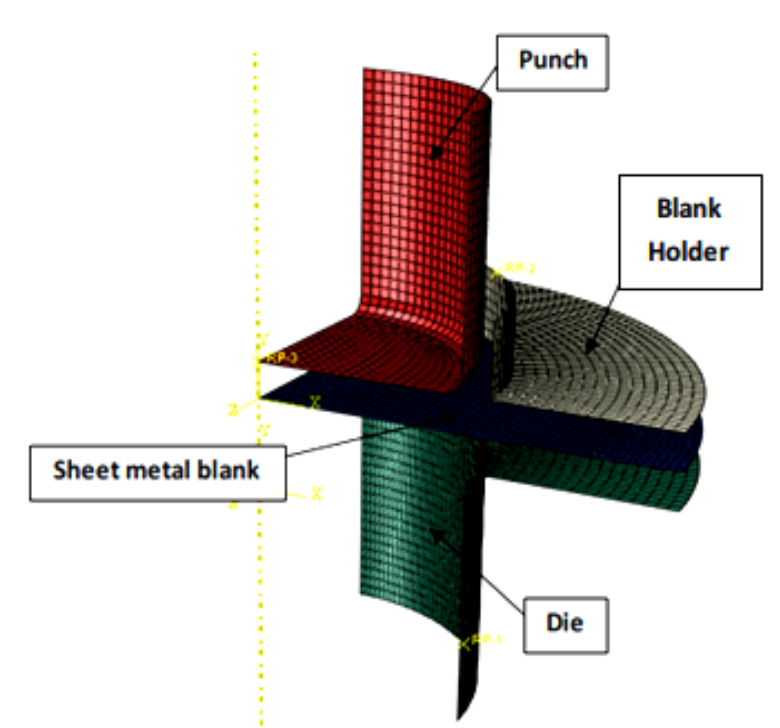

Figure 3. The model assembly scheme in FEM

\subsection{Material Properties}

The blank is made of mild steel [10]. The material is modeled as an elastic-plastic material with isotropic elasticity, using the Hill anisotropic yield criterion for the plasticity to describe the anisotropic characteristics of the sheet metal within the simulation program (ABAQUS/Explicit). Figure 4 shows the true stress, true strain curve of the material behavior, whilst Table 2 shows the material properties.

Table 2. Blank Material

\begin{tabular}{|c|c|c|}
\hline Young's modulus (E) & \multicolumn{2}{|c|}{$206 \mathrm{GPa}$} \\
\hline Poisson's ratio $(v)$ & \multicolumn{2}{|c|}{0.3} \\
\hline Density $(\rho)$ & \multicolumn{2}{|c|}{$7800 \mathrm{Kg} / \mathrm{m} 3$} \\
\hline \multirow{5}{*}{\begin{tabular}{c} 
Yield stress $\sigma_{0}$ \\
\multirow{2}{*}{$\begin{array}{c}\text { Anisotropic yield } \\
\text { criterion }\end{array}$}
\end{tabular}} & $\mathrm{R}_{11}$ & $167 \mathrm{MPa}$ \\
\cline { 2 - 3 } & $\mathrm{R}_{22}$ & 1.0402 \\
\cline { 2 - 3 } & $\mathrm{R}_{33}$ & 1.24897 \\
\cline { 2 - 3 } & $\mathrm{R}_{12}$ & 1.07895 \\
\cline { 2 - 3 } & $\mathrm{R}_{13}$ & 1 \\
\cline { 2 - 3 } & $\mathrm{R}_{23}$ & 1 \\
\hline
\end{tabular}

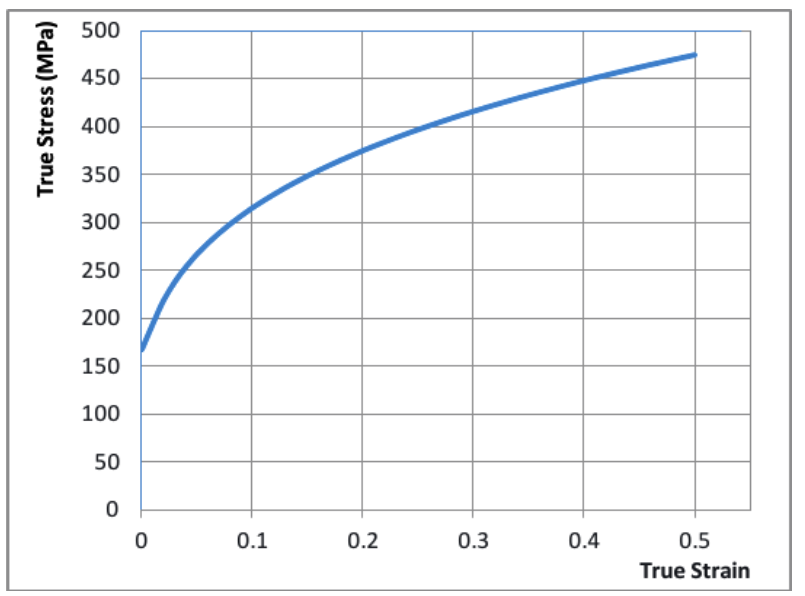

Figure 4. Plastic True Stress vs. Plastic True Strain curve of mild steel 


\subsection{Die Design Parameters}

The die design parameters are classified into two categories.

1st. category is the tool geometry parameters in drawing operations

(1). Die shoulder radius $\left(r_{d}\right)$

(2). Punch nose radius $\left(\mathrm{r}_{\mathrm{p}}\right)$

(3). Sheet metal thickness (t)

(4). Radial clearance (wc)

2nd category is the process operating parameters

(5). Blank holder force (BHF)

(6). Lubrication:

- Coefficient of friction between punch/blank $\left(\mu_{\mathrm{p}}\right)$,

- Coefficient of friction between holder/blank $\left(\mu_{\mathrm{h}}\right)$,

- And coefficient of friction between die/blank $\left(\mu_{\mathrm{d}}\right)$

The study of the influence of the tool geometry parameters and the physical parameters on thinning of sheet metal in the deep drawing process have been made, according to recommended geometrical values of these parameters from the code, Table 3[11].

\begin{tabular}{|c|c|c|}
\multicolumn{2}{c|}{} & \multicolumn{2}{c|}{ Table 3. Quoted parameters } \\
\hline \multirow{2}{*}{$\begin{array}{c}\text { Die shoulder } \\
\text { radius }\left(\mathrm{r}_{\mathrm{d}}\right)\end{array}$} & $\mathrm{rd}=(6$ to 10$) \mathrm{t}$ & For first draw \\
\hline \multirow{2}{*}{$\begin{array}{c}\text { Punch nose } \\
\left.\text { radius ( } \mathrm{r}_{\mathrm{p}}\right)\end{array}$} & $\mathrm{rp}=(3$ to 4$) \mathrm{t}$ & For $6.3 \mathrm{~mm}<=\mathrm{dp}<100 \mathrm{~mm}$ \\
\cline { 2 - 4 } & $\mathrm{rp}=(4$ to 5$) \mathrm{t}$ & For $100 \mathrm{~mm}<=\mathrm{dp}<200 \mathrm{~mm}$ \\
\cline { 2 - 3 } & $\mathrm{rp}=(5$ to 7$) \mathrm{t}$ & For $200 \mathrm{~mm}<=\mathrm{dp}$ \\
\hline $\begin{array}{c}\text { Radial } \\
\text { clearance } \\
\text { (wc) }\end{array}$ & $\mathrm{wc}=(1.75$ to 2.25$) \mathrm{t}$ & For steel, deep drawing \\
\hline
\end{tabular}

\section{Validation of The Model}

Colgan and Monaghan [2], performed an experimental and numerical analysis of the process and therefore a comparison between the present work against the values which have been recorded for the blank thickness of the deep drawn cup may be used to validate the model. Figure 5 shows the typical shape characteristics and thickness variations of a partially drawn blank. Thickening occurs in the flange area and some stretching and necking occurs in the sidewall, just above the punch nose radius [2].

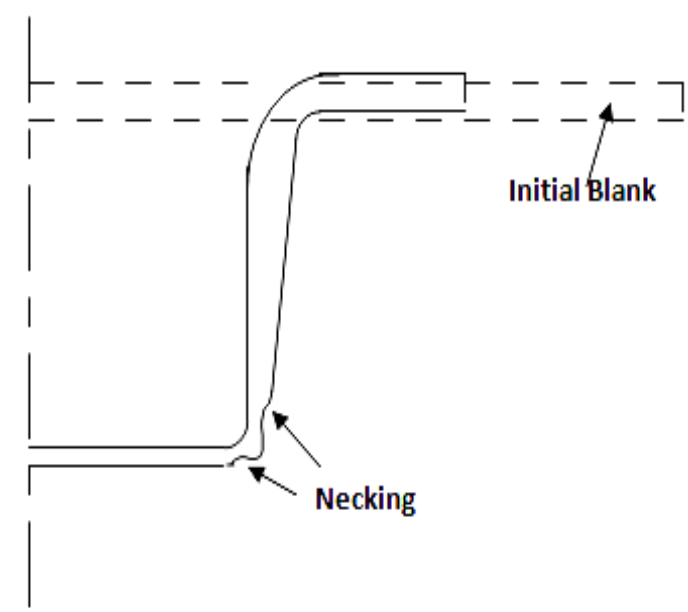

Figure 5. Deformation and necking of workpiece

They measured the sheet metal blank thickness at 8 locations. Therefore, 8 values of thickness were taken from the generated data, at distances corresponding to these lengths as shown in Figure 6 and Figure 7.

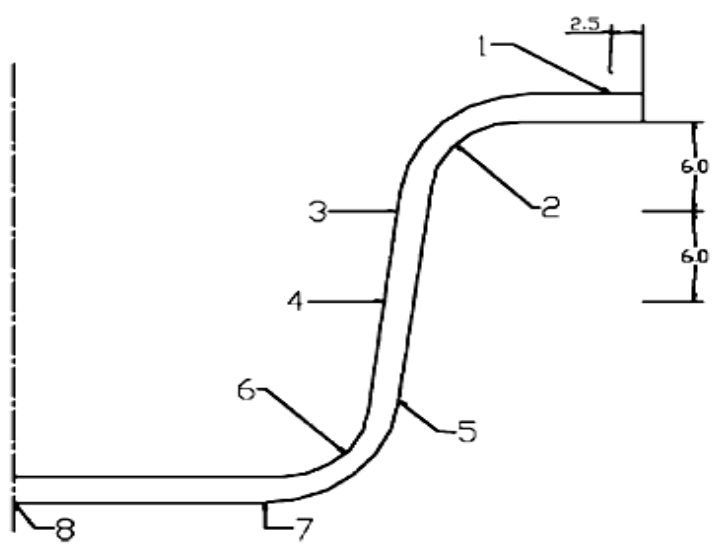

Figure 6. Thickness measurement locations on the drawn cup for the model validation

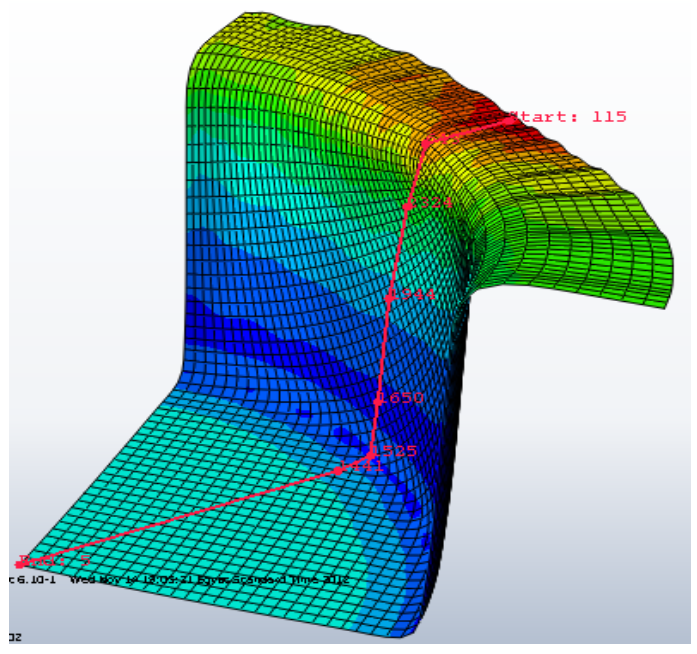

Figure 7. Corresponding thickness values locations for the model validation

Table 4 and Table 5 show the model dimensions and materials properties respectively. The present model is 
made and analyzed on ABAQUS/EXPLICIT FEA program.

Table 4. Geometrical Parameters

\begin{tabular}{|c|c|}
\hline Blank size radius (BR) & $38 \mathrm{~mm}$ \\
\hline Blank thickness (t) & $1 \mathrm{~mm}$ \\
\hline Punch radius (PR) & $19.7 \mathrm{~mm}$ \\
\hline Punch nose radius ( $\mathrm{r}_{\mathrm{p}}$ ) & $2 \mathrm{~mm}$ \\
\hline Die radius (DR) & $20.85 \mathrm{~mm}$ \\
\hline Die shoulder radius ( $\mathrm{r}_{\mathrm{d}}$ ) & $2 \mathrm{~mm}$ \\
\hline Radial clearance (wc) & $1.15 \mathrm{~mm}$ \\
\hline Cup height of the first draw (h) & $20 \mathrm{~mm}$ \\
\hline
\end{tabular}

Table 5. Physical Parameters
\begin{tabular}{|c|c|}
\hline Young's modulus $(\mathrm{E})$ & $200 \mathrm{GPa}$ \\
\hline Poisson's ratio $(v)$ & 0.3 \\
\hline Tangent modulus $(\mathrm{Et})$ & $0.5 \mathrm{GPa}$ \\
\hline Density $(\rho)$ & $7800 \mathrm{Kg} / \mathrm{m} 3$ \\
\hline Yield stress $\left(\sigma_{\mathrm{o}}\right)$ & $200 \mathrm{MPa}$ \\
\hline Friction Coefficient $(\mu)$ & 0.1 \\
\hline Blank holder force $(\mathrm{BHF})$ & $18 \mathrm{KN}$ \\
\hline
\end{tabular}

The values obtained from the present results correspond to the thickness at the closest node to the corresponding locations given by Colgan et al. [2] along the cup cross section. Obviously these locations cannot be exactly the same due to automatic mesh generation, and therefore small differences in thickness variations are expected. Figure 8 depicts the location of reference nodes given by Colgan et al. [2], whilst both locations and values from the present model are demonstrated in Figure 9.

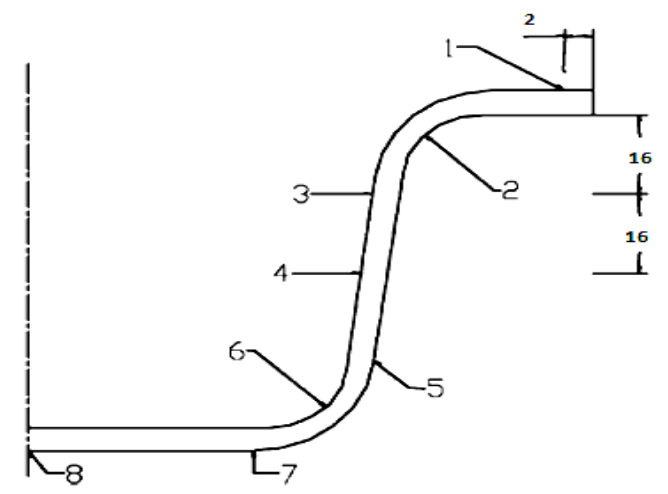

Figure 8. Thickness measured locations on the drawn cup

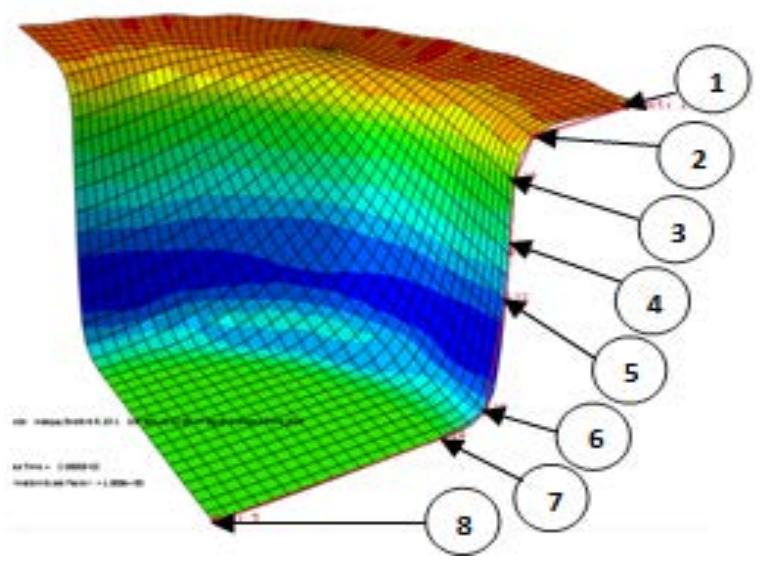

Figure 9. Thickness locations on the drawn cup for the present FEA model
It is shown in Table 6 that the average thickness distribution in the blank of the present FEA model is more close to the average obtained from the experimental results [2]. Furthermore the present results are very close to their numerical results with differences which do not exceed $2.9 \%$, on average. It is even more closer to their experimental results with differences less than $0.6 \%$ on average.

\begin{tabular}{|c|c|c|c|}
\multicolumn{1}{|c|}{ Table 6. Comparison of thicknesses } \\
\hline & Experimental [2] & FEA Predicted [2] & $\begin{array}{c}\text { Present } \\
\text { FEA }\end{array}$ \\
\hline 1 & 1.132 & 1.11 & 1.13926 \\
\hline 2 & 1.032 & 1.08 & 1.08072 \\
\hline 3 & 0.888 & 1.01 & 0.97214 \\
\hline 4 & 0.83 & 0.955 & 0.83777 \\
\hline 5 & 0.823 & 0.799 & 0.75774 \\
\hline 6 & 0.871 & 0.844 & 0.78593 \\
\hline 7 & 0.966 & 0.942 & 0.94598 \\
\hline 8 & 0.979 & 0.958 & 0.95945 \\
\hline average & 0.94013 & 0.96225 & 0.93487 \\
\hline
\end{tabular}

\section{Results and Discussion}

\subsection{Tool Geometry Parameters}

\subsubsection{Die Shoulder Radius $\left(r_{d}\right)$}

The geometry of die influences the thickness distribution and thinning of sheet metal blank in the deep drawing processes. Table 7 and Figure 10 show thickness distribution for different values of the die shoulder radius $\left(\mathrm{r}_{\mathrm{d}}\right)$. Figure 11 shows thinning of sheet metal with diverse values of the die shoulder radius $\left(\mathrm{r}_{\mathrm{d}}\right)$.

Table 7. Effect of die shoulder radius (rd) on sheet metal thickness Distribution

\begin{tabular}{|c|c|c|c|c|c|}
\hline $\begin{array}{c}\text { Measured } \\
\text { Thickness } \\
(\mathrm{mm}) \text { at } \\
\text { Locations }\end{array}$ & \multicolumn{5}{|c|}{$\mathrm{r}_{\mathrm{d}}(\mathrm{mm})$} \\
\cline { 2 - 6 } & 4 & 6 & 8 & 10 & 12 \\
\hline 1 & 1.2069 & 1.2157 & 1.2150 & 1.2065 & 1.1966 \\
\hline 2 & 1.1658 & 1.1697 & 1.1544 & 1.1541 & 1.1612 \\
\hline 3 & 1.0105 & 1.0560 & 1.0675 & 1.0830 & 1.0834 \\
\hline 4 & 0.9338 & 0.9723 & 0.9892 & 0.9972 & 1.0022 \\
\hline 5 & 0.8959 & 0.9268 & 0.9359 & 0.9458 & 0.9551 \\
\hline 6 & 0.9258 & 0.9296 & 0.9293 & 0.9310 & 0.9312 \\
\hline 7 & 0.9720 & 0.9732 & 0.9747 & 0.9747 & 0.9746 \\
\hline 8 & 0.9904 & 0.9927 & 0.9918 & 0.9923 & 0.9921 \\
\hline average & 1.0126 & 1.0295 & 1.0322 & 1.0356 & 1.0370 \\
\hline
\end{tabular}




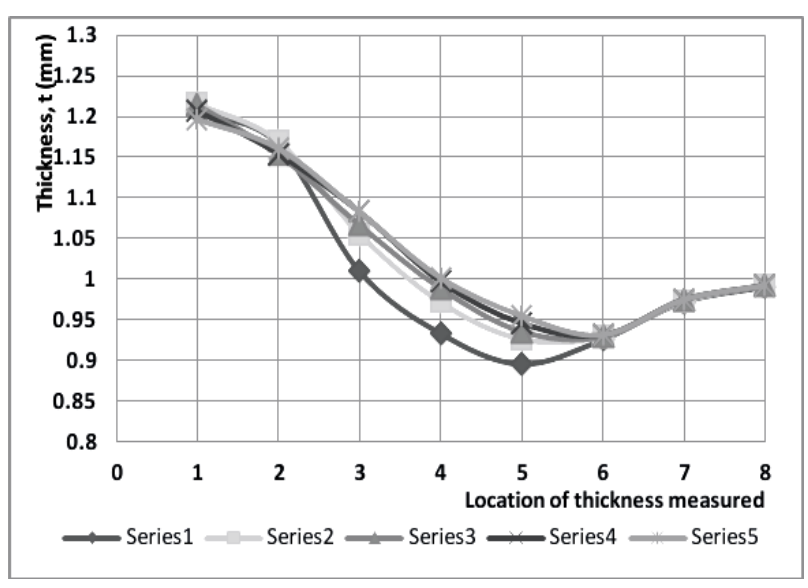

Figure 10. Distribution of sheet metal thickness with diverse values of the die shoulder radius $\left(r_{d}, \mathrm{~mm}\right)$

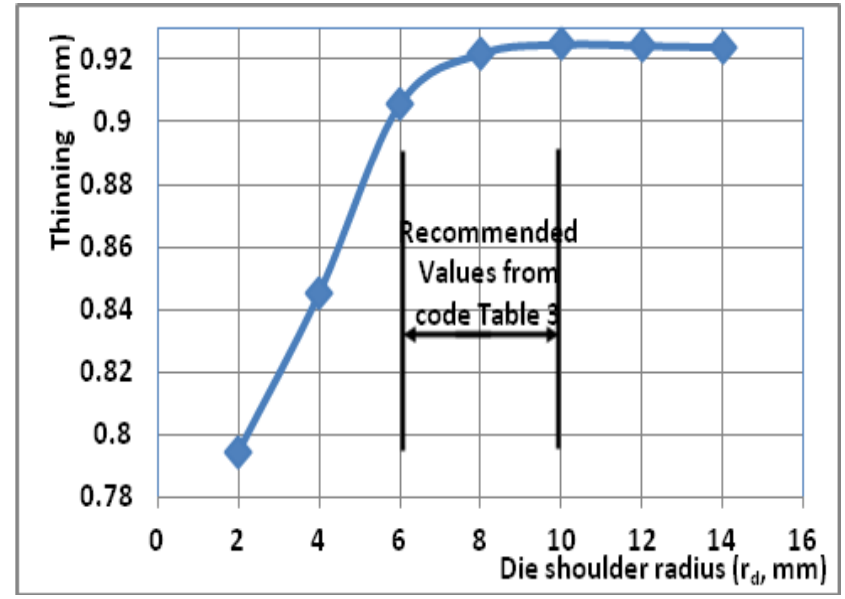

Figure 11. Variation of the sheet metal thinning with different values of the die shoulder radius $\left(r_{d}\right)$

\subsubsection{Punch Nose Radius $\left(r_{p}\right)$}

The geometry of punch influnces the thickness distribution and thinning of sheet metal blank in the deep drawing processes. Table 8 and Figure 12 show thickness distribution with different values of the punch nose radius (rp). Figure 13 shows thinning of the sheet metal with diverse values of the punch nose radius $\left(\mathrm{r}_{\mathrm{p}}\right)$.

Table 8. Effect of punch nose radius $\left(r_{p}\right)$ on sheet metal thickness distribution

\begin{tabular}{|c|c|c|c|c|c|}
\hline $\begin{array}{c}\text { Measured } \\
\text { Thickness } \\
(\mathrm{mm}) \text { at } \\
\text { Locations }\end{array}$ & \multicolumn{5}{|c|}{$\mathrm{r}_{\mathrm{p}}(\mathrm{mm})$} \\
\cline { 2 - 6 } & 2 & 3 & 4 & 5 & 6 \\
\hline 1 & 1.2208 & 1.2147 & 1.2157 & 1.1942 & 1.2002 \\
\hline 2 & 1.1580 & 1.1470 & 1.1697 & 1.1510 & 1.1710 \\
\hline 3 & 1.0443 & 1.0414 & 1.0560 & 1.0441 & 1.0551 \\
\hline 4 & 0.9717 & 0.9724 & 0.9723 & 0.9736 & 0.9734 \\
\hline 5 & 0.9286 & 0.9272 & 0.9268 & 0.9265 & 0.9250 \\
\hline 6 & 0.9203 & 0.9223 & 0.9296 & 0.9383 & 0.9440 \\
\hline 7 & 0.9812 & 0.9786 & 0.9732 & 0.9695 & 0.9680 \\
\hline 8 & 0.9890 & 0.9914 & 0.9927 & 0.9904 & 0.9907 \\
\hline average & 1.0267 & 1.0244 & 1.0295 & 1.0234 & 1.0284 \\
\hline
\end{tabular}

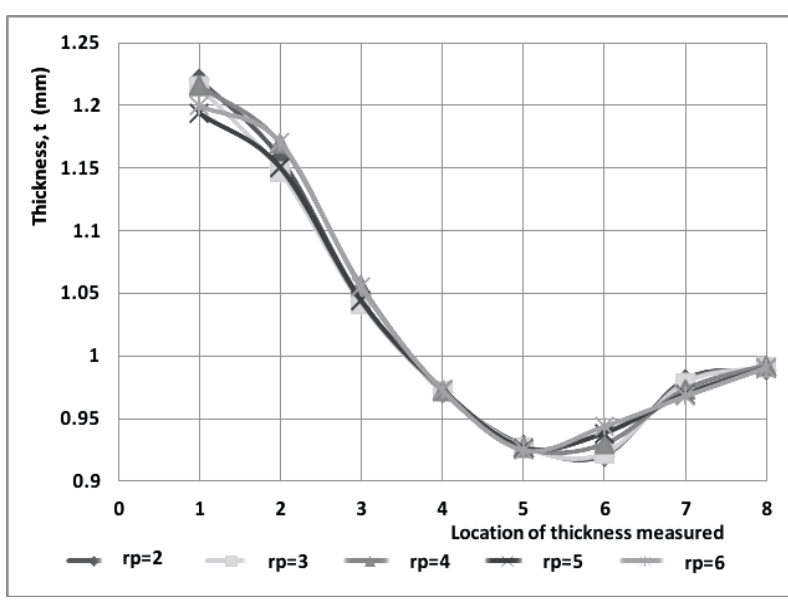

Figure 12. Distribution of sheet metal thickness with diverse values of the punch nose radius $\left(r_{p}, m m\right)$

It is shown that for a punch nose radius $\left(r_{p}\right)$ that is less than three times the thickness of the blank (t), the cup fails due to increased thinning, whilst for $\left(r_{p}\right)$ greater than 3t, thinning is slightly stable.

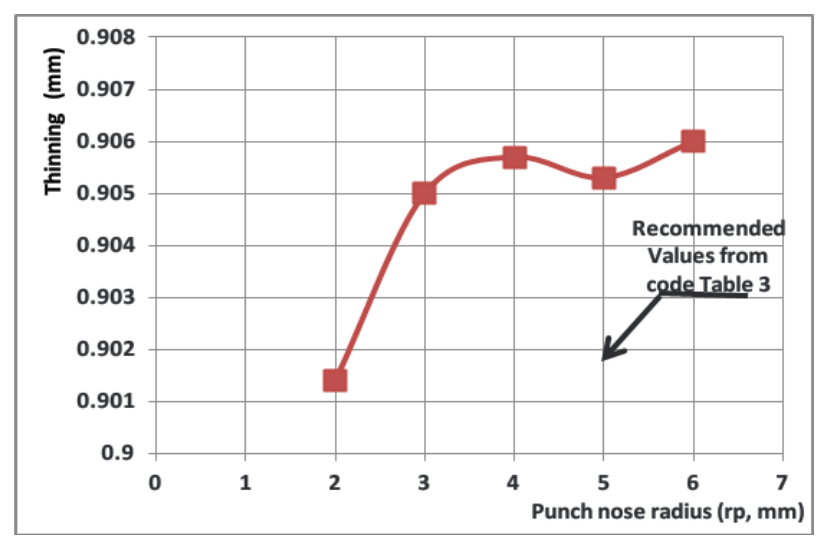

Figure. 13. Variation of the sheet metal thinning with different values of the punch nose radius $\left(r_{p}\right)$

\subsubsection{Blank Thickness (t)}

The original blank thickness has some effect on the thickness distribution and thinning of sheet metal blank in the deep drawing processes. Table 9 and Figure 14 show thickness distribution with several values of the blank thickness (t). Figure 15 shows the percentage of thinning of sheet metal with different blank thickness (t).

\section{Table 9. Effect of blank thickness (t) on sheet metal thickness} distribution

\begin{tabular}{|c|c|c|c|c|c|}
\hline $\begin{array}{c}\text { Measured } \\
\text { Thickness } \\
(\mathrm{mm}) \text { at } \\
\text { Locations }\end{array}$ & \multicolumn{5}{|c|}{$\mathrm{t}(\mathrm{mm})$} \\
\cline { 2 - 6 } & 0.6 & 0.8 & 1 & 1.4 & 1.8 \\
\hline 1 & 0.6973 & 0.9416 & 1.2157 & 1.6606 & 2.1740 \\
\hline 2 & 0.6676 & 0.9006 & 1.1697 & 1.6034 & 2.0951 \\
\hline 3 & 0.6292 & 0.8423 & 1.0560 & 1.4283 & 1.8505 \\
\hline 4 & 0.5854 & 0.7811 & 0.9723 & 1.3320 & 1.7042 \\
\hline 5 & 0.5663 & 0.7497 & 0.9268 & 1.2668 & 1.5952 \\
\hline 6 & 0.5592 & 0.7499 & 0.9296 & 1.2550 & 1.6059 \\
\hline
\end{tabular}




\begin{tabular}{|c|c|c|c|c|c|}
\hline 7 & 0.5839 & 0.7795 & 0.9732 & 1.3493 & 1.7474 \\
\hline 8 & 0.5896 & 0.7917 & 0.9927 & 1.3732 & 1.7873 \\
\hline average & 0.6098 & 0.8171 & 1.0295 & 1.4086 & 1.8200 \\
\hline
\end{tabular}

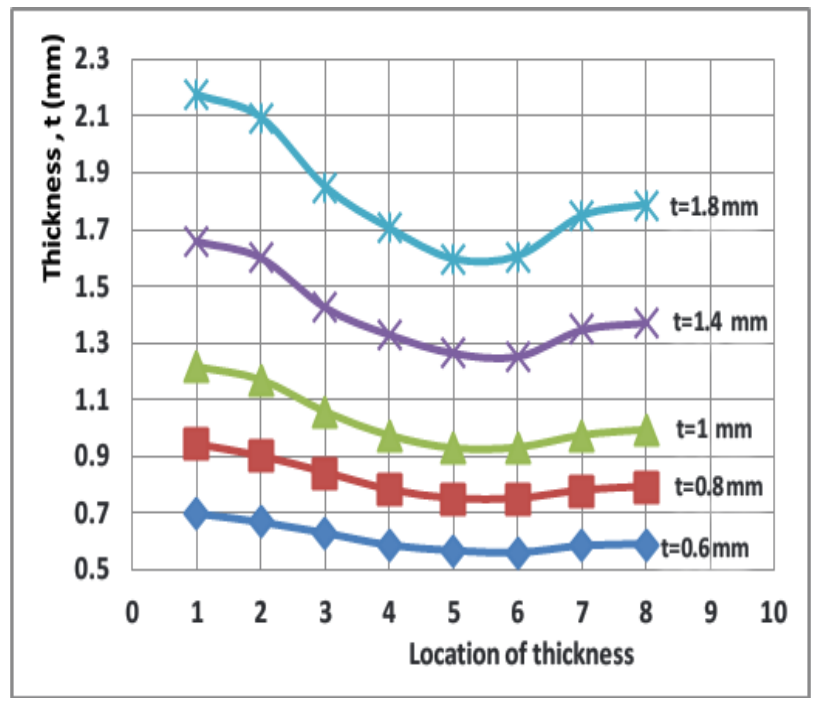

Figure 14. Distribution of sheet metal thickness with several values of the blank thickness ( $\mathrm{t}$ )

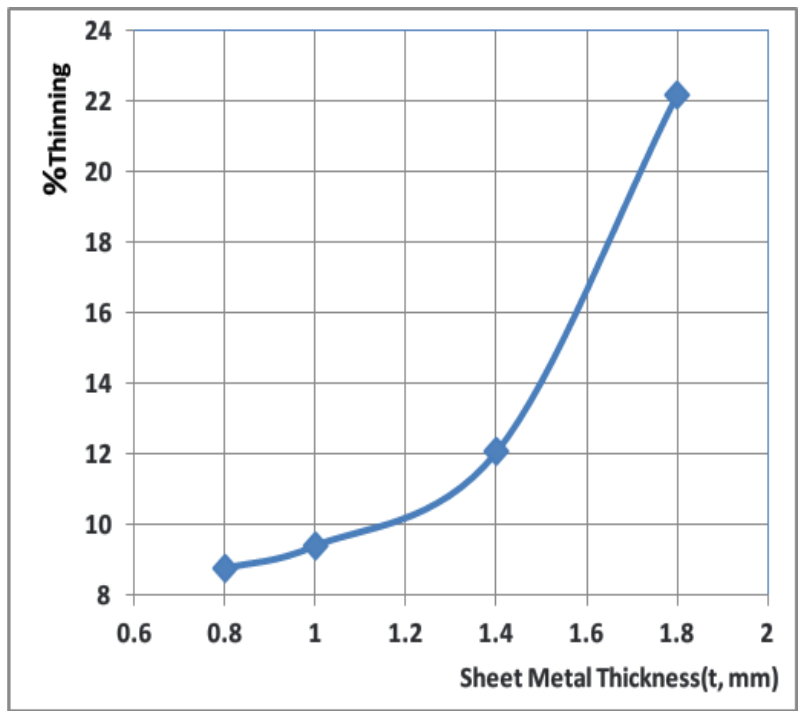

Figure 15. Variation of \% the sheet metal thinning with variation of the blank thickness (t)

It has been shown that the average distribution of the blank thickness is increasing with increasing of the blank thickness. Also, the \% of thinning is increasing with increasing of the blank thickness. Taking into account, the blank thickness and the punch diameter affect the Limiting drawing ratio (LDR) decreases as the relative punch diameter increases; see the Figure 16 [13]. Slightly thicker materials can be gripped better during the deep drawing process. Also, thicker sheets have more volume and hence can be stretched to a greater extent with increasing in thinning.

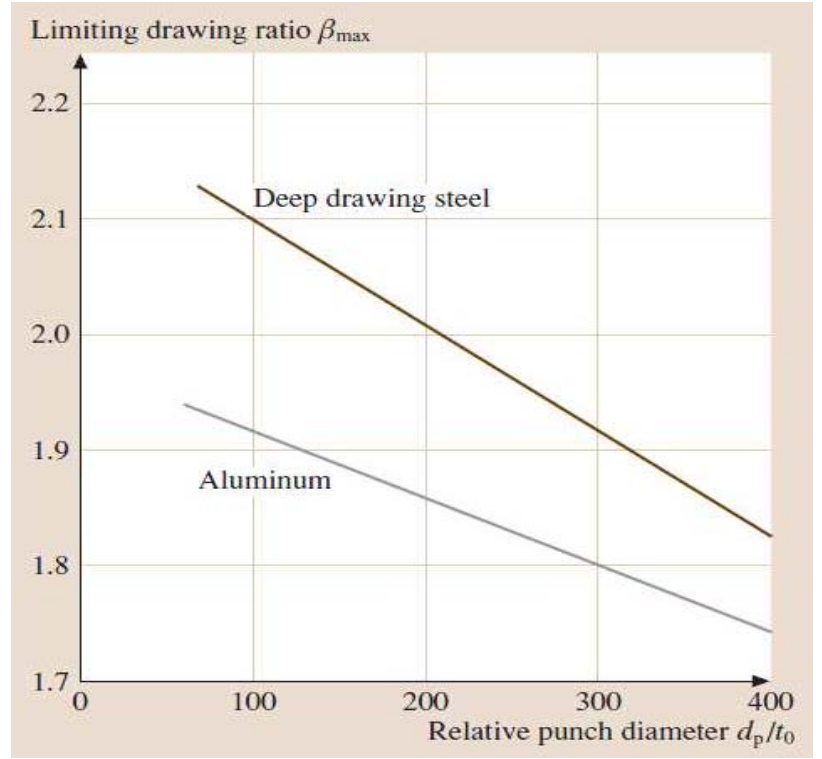

Figure 16. Effect of relative punch diameter on the limiting drawing ratio [13]

\subsubsection{Radial Clearance (wc)}

Radial clearance is an important parameter, formulated as the difference between die radius and punch radius (wC $=\mathrm{DR}-\mathrm{PR}$ ). Table 10 and Figure 17 show thickness distribution with different values of the radial clearance (wc). Figure 18 shows thinning of the blank with diverse values of the radial clearance (wc).

Table 10. Effect of radial clearance (wc) on sheet metal thickness distribution

\begin{tabular}{|c|c|c|c|c|c|c|c|}
\hline $\begin{array}{c}\text { Measured } \\
\text { Thickness } \\
(\mathrm{mm}) \text { at } \\
\text { Locations }\end{array}$ & 0.4 & 0.8 & 1.2 & 1.67 & 2 & 2.4 & 2.8 \\
\cline { 2 - 8 } & 1.1159 & 1.2552 & 1.2094 & 1.2157 & 1.1927 & 1.1964 & 1.1929 \\
\hline 1 & 1.1084 & 1.1442 & 1.1503 & 1.1697 & 1.1430 & 1.1750 & 1.1533 \\
\hline 2 & 1.1009 & 1.0038 & 1.0464 & 1.0560 & 1.0393 & 1.0475 & 1.0410 \\
\hline 3 & 0.7842 & 0.9697 & 0.9740 & 0.9723 & 0.9727 & 0.9706 & 0.9734 \\
\hline 4 & 0.8708 & 0.9248 & 0.9270 & 0.9268 & 0.9254 & 0.9246 & 0.9273 \\
\hline 5 & 0.9258 & 0.9300 & 0.9295 & 0.9296 & 0.9298 & 0.9298 & 0.9295 \\
\hline 6 & 0.9714 & 0.9757 & 0.9737 & 0.9732 & 0.9732 & 0.9730 & 0.9728 \\
\hline 7 & 0.9824 & 0.9938 & 0.9930 & 0.9927 & 0.9923 & 0.9923 & 0.9917 \\
\hline 8 & 0.9825 & 1.0247 & 1.0254 & 1.0295 & 1.0211 & 1.0261 & 1.0227 \\
\hline average
\end{tabular}

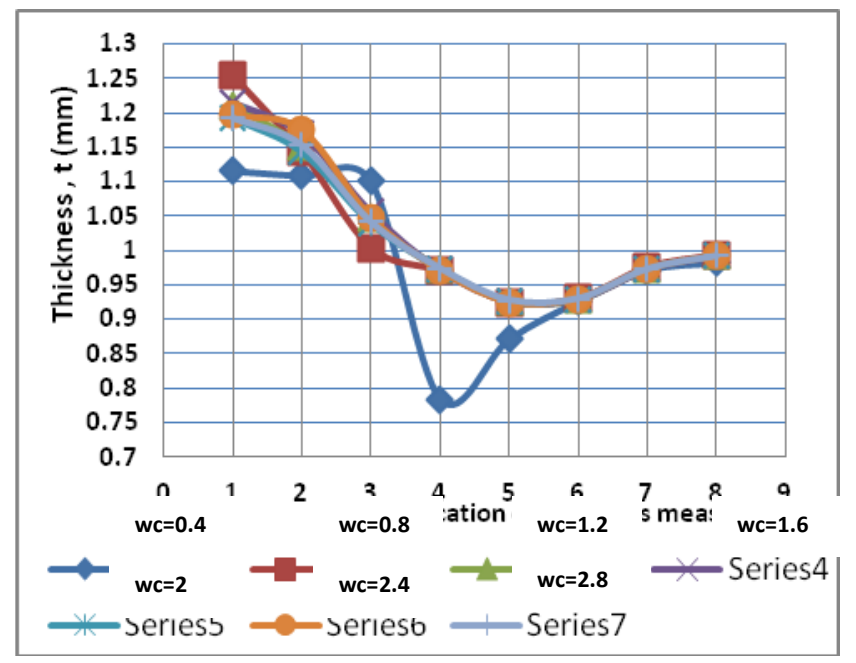


Figure 17. Distribution of sheet metal thickness with several values of the radial clearance ( $\mathrm{w} \mathrm{c},(\mathrm{mm}))$

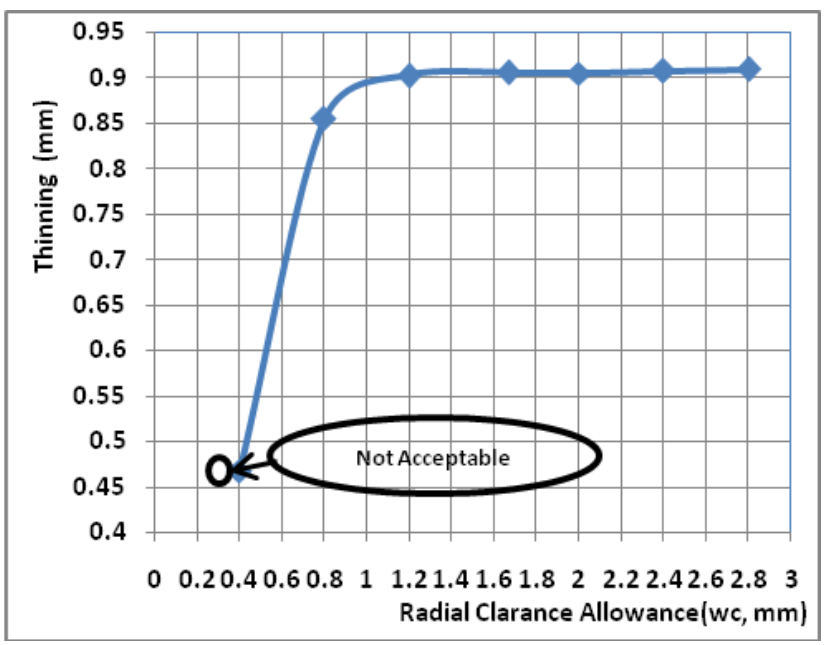

Figure 18. Variation of the sheet metal thinning with different values of the radial clearance (w c, $(\mathrm{mm})$ )

It is shown that the distribution in sheet metal thickness is increasing with reducing the radial clearance (wc). In addition, for the radial clearance (wc) that is less than the blank thickness (t), the cup fails due to increased thinning. Whilst for the radial clearance (wc) greater than the blank thickness (t), thinning is stable. The radial clearance which is less than (0.5t) is not acceptable because the percentage of reduction in thickness is more than $45 \%$, while the maximum allowable percentage of reduction in thickness is $45 \%$ [11].

\subsection{Physical Parameters}

\subsubsection{Blank Holder Force (BHF)}

The blank holder force (BHF) required to hold a blank flat for a cylindrical draw varies from very little to a maximum of one third of the drawing pressure [14]. Table 11 and Figure 19 show thickness distribution with different values of the blank holder force (BHF). Figure 20 shows thinning of the blank with the variation of the blank holder force (BHF).

Table 11. Effect of blank holder force (BHF) on sheet metal thickness distribution

\begin{tabular}{|c|c|c|c|c|c|c|c|}
\hline $\begin{array}{c}\text { Measured } \\
\text { Thickness } \\
(\mathrm{mm}) \text { at } \\
\text { Locations }\end{array}$ & 0.1 & 0.5 & 1 & 3 & 5 & 8 & 10 \\
\hline & 1.1683 & 1.2157 & 1.1815 & 1.1831 & 1.2107 & 1.1908 & 1.1872 \\
\hline 1 & 1.1908 & 1.1697 & 1.1031 & 1.1402 & 1.1211 & 1.1309 & 1.1309 \\
\hline 2 & 1.0555 & 1.0560 & 1.0288 & 1.0587 & 09850 & 1.0231 & 1.0318 \\
\hline 3 & 0.9735 & 0.9723 & 0.9464 & 0.9698 & 0.9591 & 0.9148 & 0.9059 \\
\hline 4 & 0.9264 & 0.9268 & 0.9048 & 0.9019 & 0.9068 & 0.8968 & 0.8961 \\
\hline 5 & 0.9276 & 0.9296 & 0.8797 & 0.8844 & 0.8861 & 0.8681 & 0.8529 \\
\hline 6 & 0.9726 & 0.9732 & 0.9511 & 0.9480 & 0.9544 & 0.9472 & 0.9415 \\
\hline 7 & 0.9921 & 0.9927 & 0.9663 & 0.9696 & 0.9702 & 0.9619 & 0.9588 \\
\hline 8 & 1.0259 & 1.0295 & 0.9952 & 1.0070 & 0.9992 & 0.9917 & 0.9881 \\
\hline average & & & & & & & \\
\hline
\end{tabular}

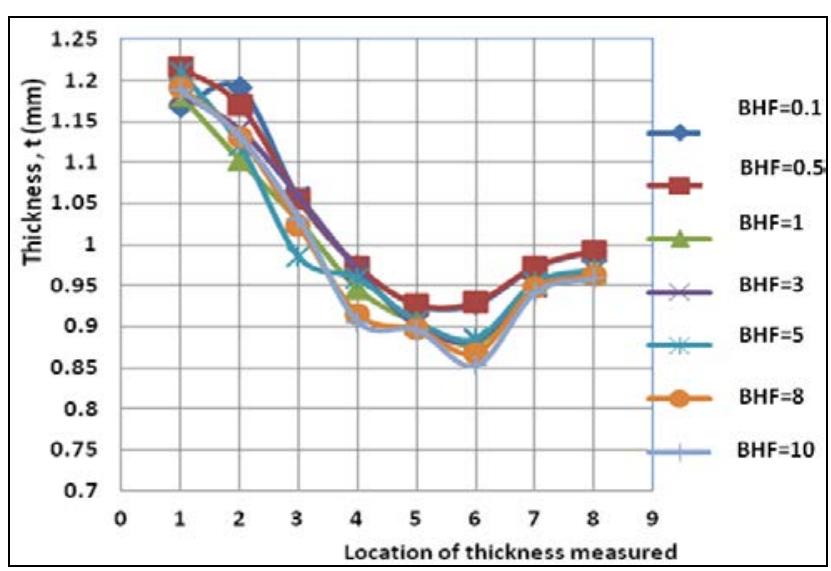

Figure 19. Distribution of sheet metal thickness with different values of the blank holder force (BHF,( ton))

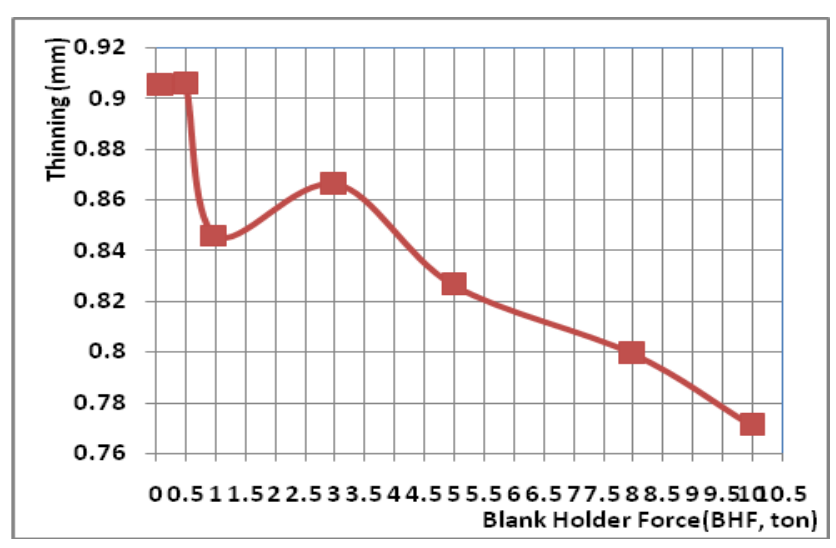

Figure 20. Variation of the sheet metal thinning with different values of the blank holder force (BHF, (ton))

The higher the blank-holder force, the greater will be the strain over the punch face, however the process is limited by the strain in the side-wall. If the tension reaches its maximum value, the side-wall will fail by splitting [15]. It has been shown that the cup collapse due to thinning with the increase of the blank holder force (BHF) over 0.5 ton (recommended value from code).

\subsubsection{Friction Parameters}

In Sheet Metal Forming processes, such as deep drawing, friction plays an important role. Together with the deformation of the sheet, the friction determines the required punch force and the blank holder force. Consequently, the friction influences the energy which is needed to deform a sheet material. Friction also influences the stresses and strains in the work piece material and, hence, the quality of the product. Therefore, it is important to control the friction between the tool and the work piece.

During deep drawing, hollow bodies are produced from metal blanks using punches, dies and blank holders. In no other forming operation are the friction and, as a result, the lubricating conditions so complex. In one drawing operation, a particularly low coefficient of friction is required in one area and a particularly high coefficient of friction in another.

The friction conditions when drawing can be best explained by means of the example of drawing a cylindrical cup. Figure 21 shows the different friction 
areas and generally illustrates the deep drawing operation [16].

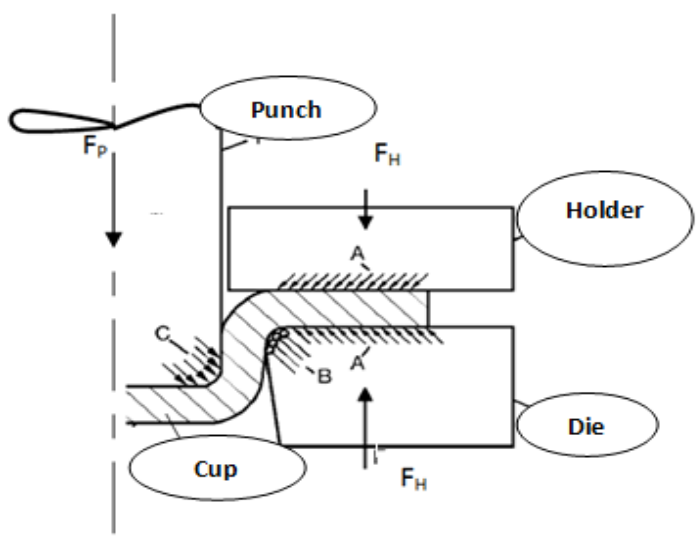

Figure 21. Friction areas when a deep drawing a cup. A, friction area between sheet metal blank and holder and sheet metal blank die; B, friction area between sheet metal blank and the die radius; $\mathrm{C}$, friction area between sheet metal blank and the punch edges; FP, total drawing force; FH, blank holder force

\subsubsection{Coefficient of Friction Between Punch/Blank $\left(\mu_{\mathrm{p}}\right)$}

The drawing force in the flange, necessary to form the sheet metal, is applied by the punch on the base of the cup and transferred through the wall into the flange. This transmission of force calls for the highest possible coefficient of friction on the punch edge. This demonstrates the first significant rule for lubrication. In this case: neither the punch nor the sheet metal blank should be lubricated in this area. Even if this consideration was optimal for an isolated forming operation and force transfer, one still must consider punch wear. This friction area requires lubrication in the boundary mode with a high coefficient of friction and anti-wear behavior [16].

Table 12 and Figure 22 show thickness distribution with different values of the coefficient of friction between punch/blank $\left(\mu_{\mathrm{p}}\right)$. Figure 23 shows thinning of the blank with the variation of the coefficient of friction between punch/blank $\left(\mu_{\mathrm{p}}\right)$.

Table 12. Effect of punch coefficient of friction $\left(\mu_{p}\right)$ on sheet metal thickness distribution

\begin{tabular}{|c|c|c|c|c|c|c|c|}
\hline $\begin{array}{c}\text { Measured } \\
\text { Thickness } \\
(\mathrm{mm}) \text { at } \\
\text { Locations }\end{array}$ & \multicolumn{7}{|c|}{$\mu_{\mathrm{p}}$} \\
\cline { 2 - 8 } & 0.05 & 0.1 & 0.25 & 0.5 & 0.7 & 0.9 & 1 \\
\hline 1 & 1.2033 & 1.2142 & 1.2157 & 1.2064 & 1.2037 & 1.2044 & 1.2046 \\
\hline 2 & 1.1600 & 1.1522 & 1.1697 & 1.1646 & 1.1694 & 1.1545 & 1.1446 \\
\hline 3 & 1.0528 & 1.0464 & 1.0560 & 1.0508 & 1.0490 & 1.0435 & 1.0434 \\
\hline 4 & 0.9722 & 0.9721 & 0.9723 & 0.9734 & 0.9730 & 0.9727 & 0.9729 \\
\hline 5 & 0.9176 & 0.9202 & 0.9268 & 0.9267 & 0.9272 & 0.9270 & 0.9269 \\
\hline 6 & 0.9176 & 0.9202 & 0.9296 & 0.9350 & 0.9371 & 0.9289 & 0.9397 \\
\hline 7 & 0.9427 & 0.9538 & 0.9732 & 0.9786 & 0.9795 & 0.9806 & 0.9809 \\
\hline 8 & 0.9658 & 0.9762 & 0.9927 & 0.9960 & 0.9967 & 0.9969 & 0.9971 \\
\hline average & 1.0178 & 1.0203 & 1.0295 & 1.0289 & 1.0295 & 1.0273 & 1.0263 \\
\hline
\end{tabular}

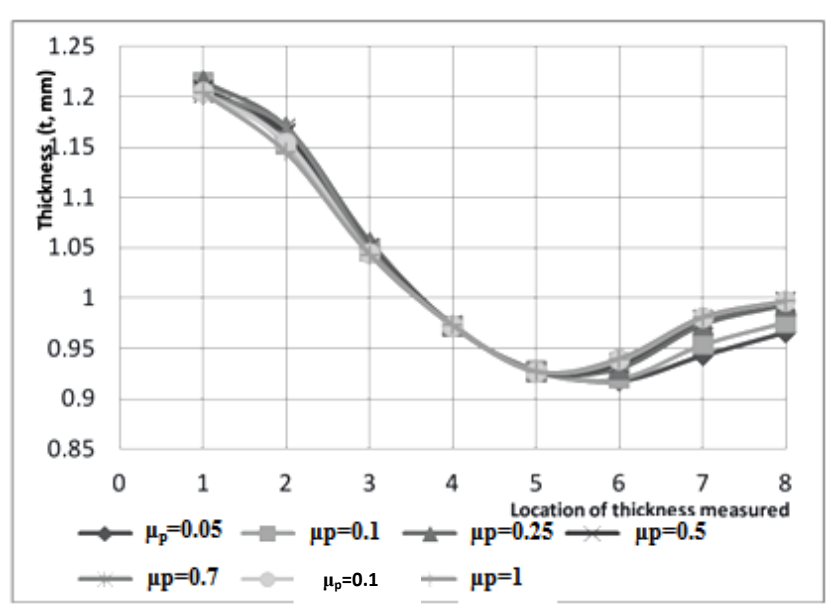

Figure 22. Distribution of sheet metal thickness with different values of the Coefficient of friction between punch/blank $\left(\boldsymbol{\mu}_{\mathrm{p}}\right)$

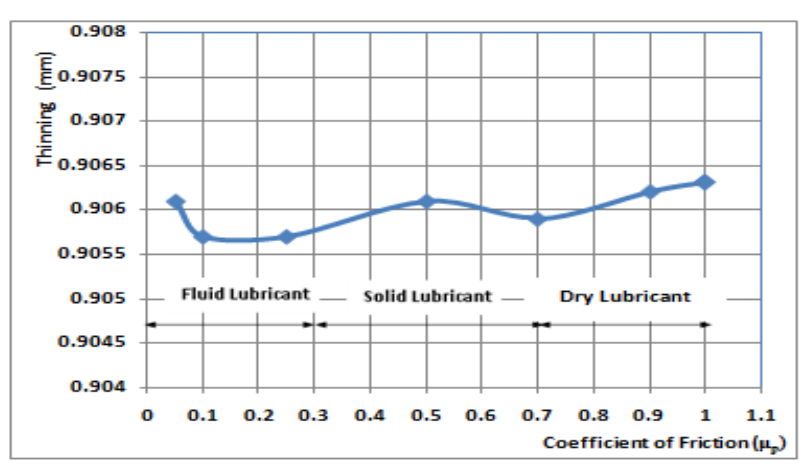

Figure 23. Variation of the sheet metal thinning with different values of the Coefficient of friction between punch/blank $\left(\boldsymbol{\mu}_{\mathrm{p}}\right)$

For fluid lubricant, it has been shown that the distribution in sheet metal thickness is decreasing with increasing of the coefficient of friction between punch/blank $\left(\mu_{\mathrm{p}}\right)$. For solid lubricant and dry lubricant, the distribution in sheet metal thickness is stable with increasing the coefficient of friction between punch/blank $\left(\mu_{\mathrm{p}}\right)$.

For fluid lubricant, it has been shown that the thinning of sheet metal is increasing by small values with increasing the coefficient of friction between punch/blank $\left(\mu_{\mathrm{p}}\right)$. On the other hand, for solid lubricant and dry lubricant, the thinning growing with rising of the coefficient of friction between punch/blank $\left(\mu_{\mathrm{p}}\right)$.

\subsubsection{Coefficient of Friction Between Holder/Blank $\left(\mu_{h}\right)$}

The main aim of deep drawing lubrication is to achieve minimum friction in the blank holder area. This includes the lubrication on the blank holder side, which, as much as possible, should be a lubricant ring in order to reduce the friction in the region of the punch edge as little as possible. However, in the case of high viscosity oils and drawing pastes, if the applied lubricant film is excessive, there is the risk that hydrostatic effects on the blank holder side of the flange can cause reduction of sheet metal contact with the blank holder resulting in wrinkling [16].

Table 13 and Figure 24 show thickness distribution with different values of the coefficient of friction between holder/blank $(\mu \mathrm{h})$. Figure 25 shows thinning of the blank 
with the variation of the coefficient of friction between holder/blank $\left(\mu_{\mathrm{h}}\right)$.

Table 13. Effect of holder coefficient of friction $\left(\mu_{h}\right)$ on sheet metal thickness distribution

\begin{tabular}{|c|c|c|c|c|c|c|c|}
\hline $\begin{array}{c}\text { Measured } \\
\text { Thickness } \\
(\mathrm{mm}) \text { at } \\
\text { Locations }\end{array}$ & 0.05 & 0.08 & 0.11 & 0.125 & 0.14 & 0.16 & 0.18 \\
\cline { 2 - 7 } & 1.2166 & 1.2162 & 1.2158 & 1.2157 & 1.2155 & 1.2157 & 1.2160 \\
\hline 2 & 1.1763 & 1.1731 & 1.1705 & 1.1697 & 1.1684 & 1.1665 & 1.1654 \\
\hline 3 & 1.0609 & 1.0580 & 1.0565 & 1.0560 & 1.0538 & 1.0531 & 1.0515 \\
\hline 4 & 0.9752 & 0.9740 & 0.9729 & 0.9723 & 0.9717 & 0.9710 & 0.9704 \\
\hline 5 & 0.9272 & 0.9271 & 0.9269 & 0.9268 & 0.9267 & 0.9266 & 0.9265 \\
\hline 6 & 0.9304 & 0.9301 & 0.9298 & 0.9296 & 0.9294 & 0.9292 & 0.9289 \\
\hline 7 & 0.9735 & 0.9734 & 0.9733 & 0.9732 & 0.9732 & 0.9731 & 0.9730 \\
\hline 8 & 0.9930 & 0.9929 & 0.9928 & 0.9927 & 0.9927 & 0.9927 & 0.9926 \\
\hline average & 1.03016 & 1.0306 & 1.0298 & 1.0295 & 1.0289 & 1.0285 & 1.0280 \\
\hline
\end{tabular}

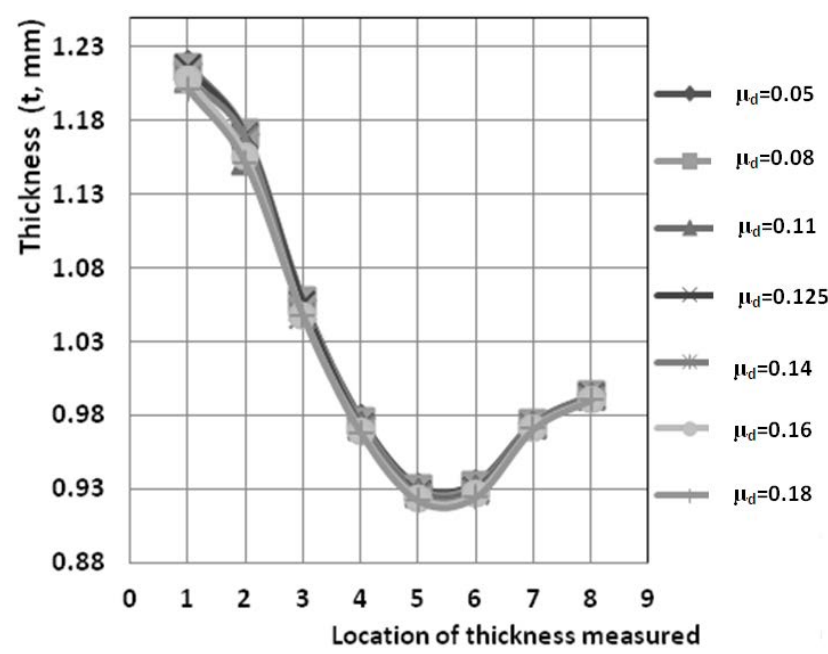

Figure 24. Distribution of sheet metal thickness with different values of the Coefficient of friction between holder/blank $\left(\boldsymbol{\mu}_{\mathbf{h}}\right)$

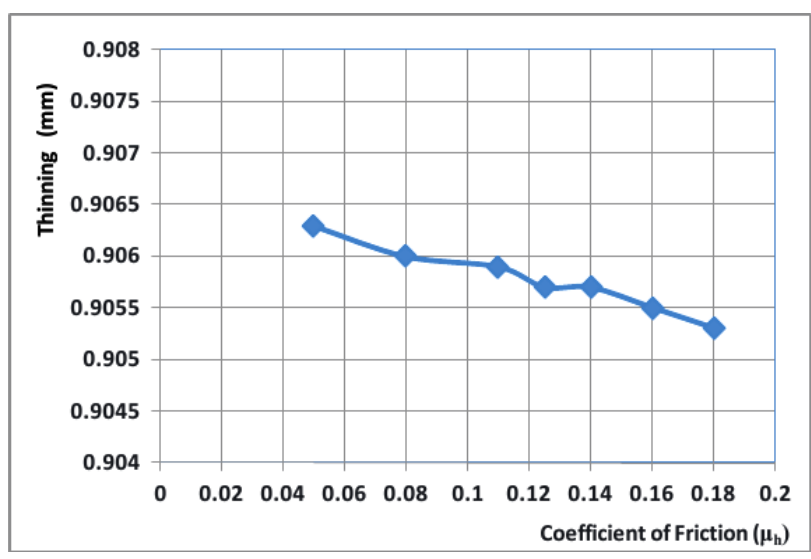

Figure 25. Variation of the sheet metal thinning with different values of the Coefficient of friction between holder/blank $\left(\boldsymbol{\mu}_{\mathbf{h}}\right)$

It is noted that the suitable lubricant for the holder/blank friction is the fluid lubricant. When the coefficient of friction between holder/blank $\left(\mu_{\mathrm{h}}\right)$ is rising, the average value of the thickness distribution is slightly stable. But the thinning of the cup is growing with rising of the coefficient of friction between holder/blank $\left(\mu_{\mathrm{h}}\right)$.

\subsubsection{Coefficient of Friction Between Die/Blank $\left(\boldsymbol{\mu}_{\mathrm{d}}\right)$}

In this case the aim of lubrication is to achieve a minimum coefficient of friction with minimum wear. Even excessive lubrication of the sheet metal surface on the die side normally does not create a problem. Only on parts with large surface areas and a high percentage of stretch drawing, such as car body parts can excessive lubricant quantities lead to unacceptable deviations in form [16].

Table 14 and Figure 26 show thickness distribution with different values of the coefficient of friction between die/blank $\left(\mu_{d}\right)$. Figure 27 shows thinning of the blank with the variation of the coefficient of friction between die/blank $\left(\mu_{\mathrm{d}}\right)$.

Table 14. Effect of die coefficient of friction $\left(\mu_{d}\right)$ on sheet metal thickness distribution

\begin{tabular}{|c|c|c|c|c|c|c|c|}
\hline \multirow{2}{*}{$\begin{array}{c}\text { Measured } \\
\text { Thickness } \\
(\mathrm{mm}) \mathrm{at} \\
\text { Locations }\end{array}$} & 0.05 & 0.08 & 0.11 & 0.125 & 0.14 & 0.16 & 0.18 \\
\cline { 2 - 8 } & 1.2188 & 1.2163 & 1.2087 & 1.2157 & 1.2067 & 1.2085 & 1.2013 \\
\hline 1 & 1.1710 & 1.1723 & 1.1522 & 1.1697 & 1.1682 & 1.1559 & 1.1511 \\
\hline 2 & 1.0582 & 1.0580 & 1.0540 & 1.0560 & 1.0475 & 1.0482 & 1.0477 \\
\hline 3 & 0.9780 & 0.9759 & 0.9737 & 0.9723 & 0.9717 & 0.9697 & 0.9684 \\
\hline 4 & 0.9320 & 0.9300 & 0.9281 & 0.9268 & 0.9260 & 0.9242 & 0.9223 \\
\hline 5 & 0.9343 & 0.9325 & 0.9304 & 0.9296 & 0.9282 & 0.9269 & 0.9249 \\
\hline 6 & 0.9753 & 0.9747 & 0.9738 & 0.9732 & 0.9728 & 0.9718 & 0.9710 \\
\hline 7 & 0.9941 & 0.9937 & 0.9931 & 0.9927 & 0.9923 & 0.9914 & 0.9906 \\
\hline 8 & 1.0327 & 1.0317 & 1.0267 & 1.0295 & 1.0269 & 1.0246 & 1.0222 \\
\hline average & & & &
\end{tabular}

These results show that the proper lubricant for the die/blank friction is the fluid lubricant. In addition, the average value of the thickness distribution is reduced with increasing the coefficient of friction between die/blank $\left(\mu_{\mathrm{d}}\right)$. Finally, the thinning in the drawn cup is increasing with increasing the coefficient of friction between die/blank $\left(\mu_{\mathrm{d}}\right)$.

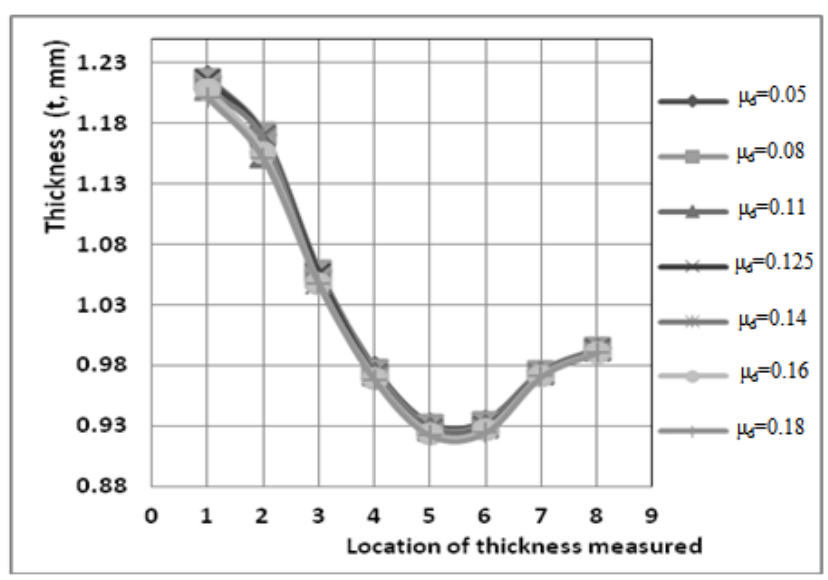


Figure 26. Distribution of sheet metal thickness with different values of the Coefficient of friction between die/blank $\left(\boldsymbol{\mu}_{\mathrm{d}}\right)$

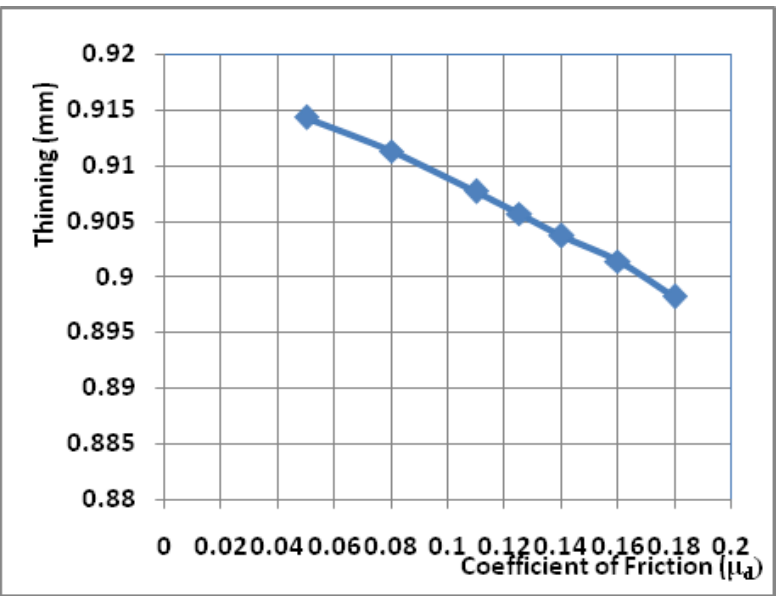

Figure 27. Variation of the sheet metal thinning with different values of the Coefficient of friction between die/blank $\left(\boldsymbol{\mu}_{\mathrm{d}}\right)$

\section{Conclusion}

Successful deep drawing depends on many parameters (geometrical parameters and physical parameters). The finite element analysis simulation (FEAS) is a powerful tool in the sheet metal die design, reducing time and trial and error efforts. A Finite Element Model is developed to reach the optimum solution without many costly trials of production which is a common practice in the traditional production approaches.

The results show that:

1 . The die shoulder radius is recommended to be about 8 times sheet thickness.

2. The punch nose radius is recommended to be greater than 3 times sheet thickness.

3. The thicker sheet metal is softer due to its increased volume which increases the thinning in sheet metal.

4. The radial clearance is recommended to be greater than the value of the sheet thickness [If the clearance is not large enough, ironing or thinning will occur].

5. Blank holder force (BHF) is recommended to be less than 3 tons to avoid increased thinning.

6 . The fluid lubricant with ( $\mu \mathrm{p}=0$ to 0.3 ), is more suitable to apply between punch and blank to reduce the thinning of the cup.
7. The fluid lubricant with ( $\mu \mathrm{h}=0$ to 0.2 ), is more suitable to apply between holder and blank. ( $\mu$ h) should be about 0.1 to reduce the thinning of the cup.

8. The fluid lubricant with ( $\mu \mathrm{d}=0$ to 0.2 ), is more suitable to apply between die and blank. ( $\mu \mathrm{d})$ is recommended to be about 0.1 to reduce the thinning of the cup.

\section{References}

[1] Mark, Richard Coles, Kirwan, J. , Food and Beverage Packaging Technology, Blackwell Publishing, London, 2011, 344.

[2] Colgan, M., and Monaghan, J., "Deep Drawing Process: Analysis and Experiment," Journal of Materials Processing Technology, 132, 35-41, 2003.

[3] Ibrahim Demirci, H., Yaşar, M., Demiray, K., "The Theoretical and Experimental Investigation of Blank Holder Forces Plate Effect in Deep Drawing Process of AL 1050 Material," Journal of Materials \& Design, 29(2), 526-532, 2008.

[4] Jawad, Waleed Khalid "Investigation of Contact Interface between the Punch and Blank in Deep Drawing Process," Journal of Engineering and Technology, 25(3), 370-382, 2007.

[5] Vladimirov, Ivaylo N., Pietryga, Michael P. Reese, Stefanie, "Anisotropic Finite Elastoplasticity with Nonlinear Kinematic and Isotropic Hardening and Application to Sheet Metal Forming", International Journal of Plasticity, 26,659-687, 2010.

[6] Fereshteh-Saniee, F., Montazeran, M.H., "A Comparative Estimation of the Forming Load in the Deep Drawing Process," Journal of Materials Processing Technology, 140, 555-561, 2003.

[7] Lange, Kurt, Handbook of Metal Forming, Society of Manufacturing Engineers, 1985.

[8] Meguid, S.A., Refaat, M.H. "Finite Element Analysis of the Deep Drawing Process using Variational Inequalities," Journal of Finite Elements in Analysis and Design, 28, 51-67, 1997.

[9] Abaqus Analysis User's Manual, Volume IV: Elements, 2011.

[10] Taylor, L. M., Cao, J., Karafillis, A. P., Boyce, M. C. "Numerical Simulations of Sheet Metal Forming," Proceedings of 2nd International Conference, NUMISHEET 93, Isehara, Japan, Ed. A. Makinovchi, 1993.

[11] Suchy, Ivana Handbook of Die Design, 2nd Edition, McGraw-Hill Publishing, 2006, 383- 400.

[12] Dieter, George E. Mechanical Metallurgy, SI Metric Edition, McGraw-Hill Series in Material Science and Engineering, 1988, 669.

[13] Grote K.-H., Antonsson E.K., Springer Handbook of Mechanical Engineering, Springer Science and Business Media, 2008, 617.

[14] David S., Jeff L., John G., Fundamentals of tool design, American Society of Tool and Manufacturing Engineers. New Delhi: Prentice Hall, 2003.

[15] Marciniak, Z. Duncan, J.L. Hu, S.J. Mechanics of Sheet Metal Forming, 2nd Edition, published by Butterworth-Heinemann, 2002, 53.

[16] Mang, Theo, Dresel, Wilfried Lubricants and Lubrication, 2nd Edition, WILEY-VCH Verlag GmbH \& Co. KGaA, Weinheim, 2007, 527-530. 